\title{
Study of the Ion Radiation Influence on the Parameters of Unijunction Transistors
}

\author{
Nikolaj Nenov ${ }^{1}$, Petar Tomchev ${ }^{2}$, Rayna Ivanova ${ }^{3}$ \\ Technical University of Gabrovo, BULGARIA, \\ 1 -e-mail:nenovtugabrovo@gmail.com, 2 -e-mail:tomchev@edasat.com,3-e-mail: \\ ivanova@tugab.bg
}

\begin{abstract}
The object of this report is study the influence of gamma quanta on some parameters of the unijunction transistors to synthesize radioisotope equipment.
\end{abstract}

Keywords - ionizing radiation, gamma quanta, unijunction transistor, volt-ampere characteristic.

\section{INTRODUCTION}

Radioactive elements and radioactive radiation are widely used in modern science. Scientists, engineers and physicians studied the movement of substances with small amounts of radioactive elements in a variety of systems. By measuring the absorption of radioactive radiation in the substance can be established other their properties, and it can be possible to monitor and study the various technological processes.

Exclusively used in practise are gamma irradiation facalities, electron accelerators and other elementary particles.

Radioactive sources together with appropriate radiation detectors are used to control a variety of automated industrial processes, such as radioactive level gauges and switches for gases, liquids and bulk materials. With their help determine the thickness of the coating density of liquids, powders or solids. Radioactive sources and radiation detectors in priority are used in hard to reach places and conditions in which direct application of other methods is difficult, such as at high temperatures and pressures, poisonous and corrosive environments, etc.

\section{DISCUSSION}

It is known, that irradiation with ionizing radiation is associated with the transmission of the additional energy of the substance contained in the irradiation field. The device of unijunction (Fig.1) transistors characterized by a $\mathrm{P}-\mathrm{N}$ transition suggesting greater susceptibility to irradiation due to the larger number of charge carriers, generated in the volume of the transition as a result of irradiation.

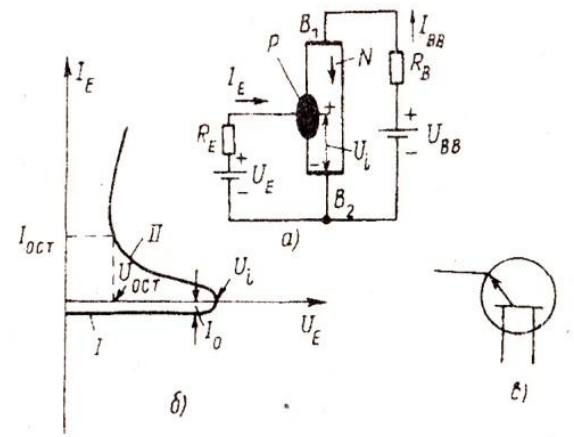

Fig.1 (a) unijunction transistors principle device; (b) volt - ampere characteristics; (c) circuit designation

There was transistor type 2N2646 studied, from which was removed some part from metal casing, which makes it possible to direct radiation. The static characteristics of the transistor shown in Fig. 2.
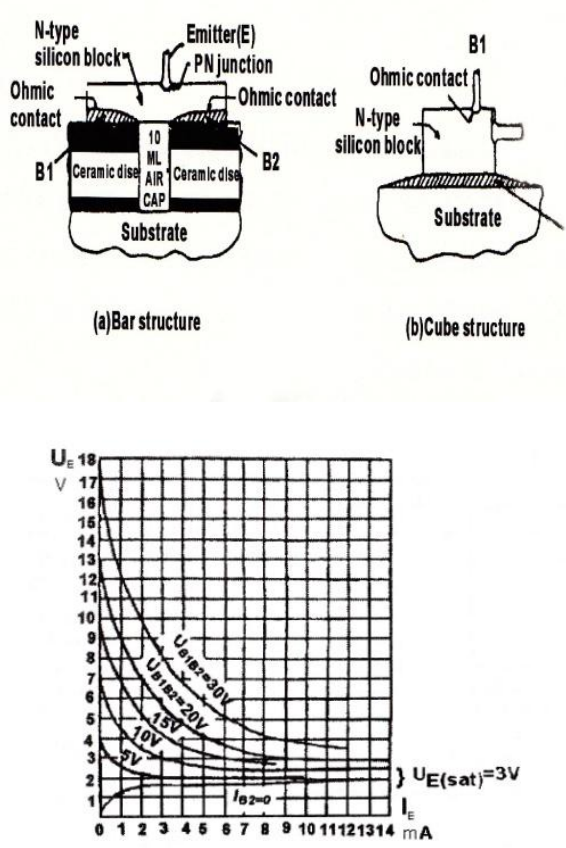

Fig.2 Structure and family static characteristics of the transistor $2 \mathrm{~N} 2646$ 
In the beginning of the research there was performed experimental design shown in Fig. 3.

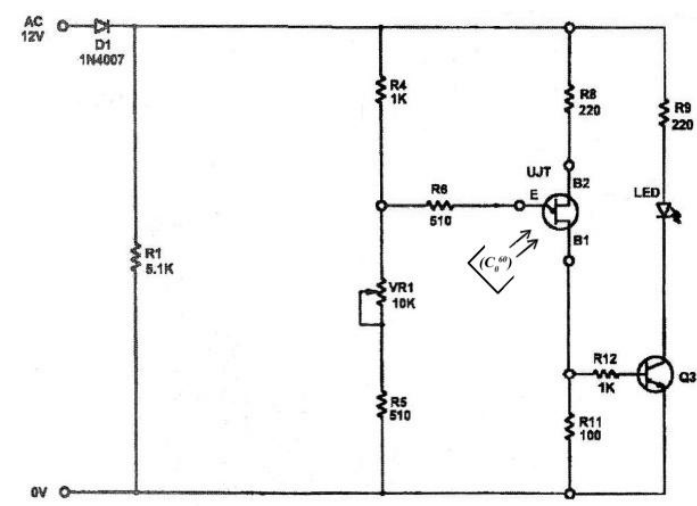

Fig.3 Schematic of the experimental set

Operating point of transistors is set by the active divider R4 - R5 and tuning precision potentiometer VR1. It allows examination of the impact of radiation with ionizing radiations at different operating points of unijunction transistor. For better visualization in scheme was added bipolar transistor (Q3) and low power holy diode (LED).

Bipolar transistor and led were added in the diagram for better visualization modes. Were captured waveforms without irradiation (Fig.4) and (Fig. 6) and after irradiation - (Fig.5) and (Fig.7).

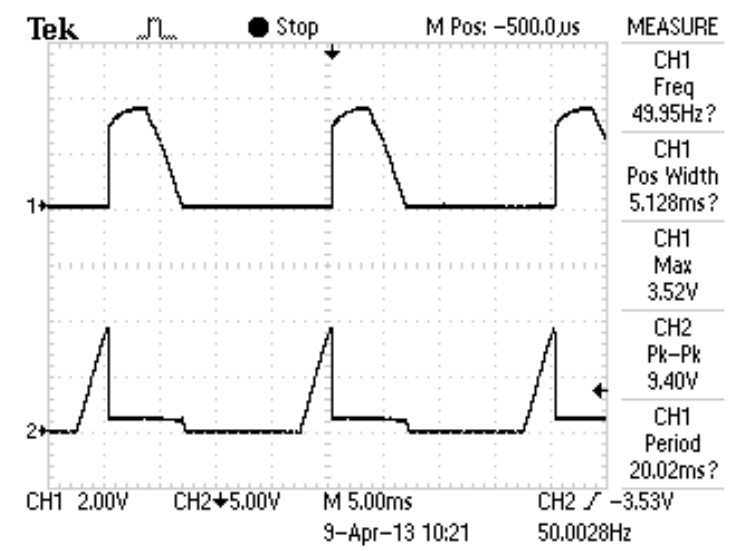

Fig.4 pulse voltage $(\mathrm{CH} 2)$ and current $(\mathrm{CH} 1)$

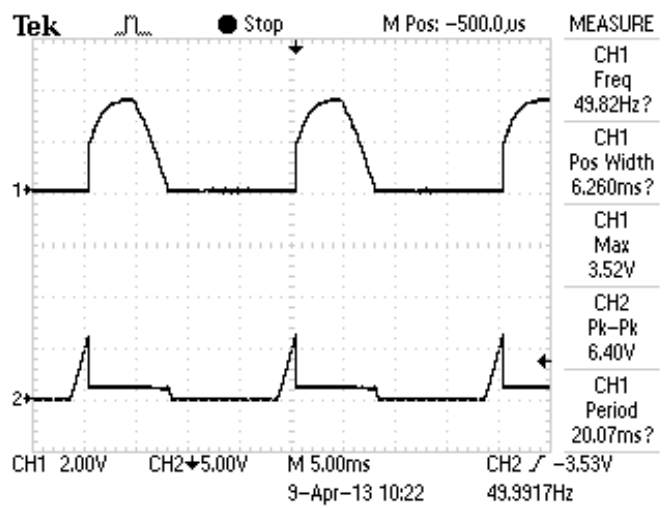

Fig.5 pulse voltage $(\mathrm{CH} 2)$ and current $(\mathrm{CH} 1)$ before irradiation after irradiation with gamma quanta

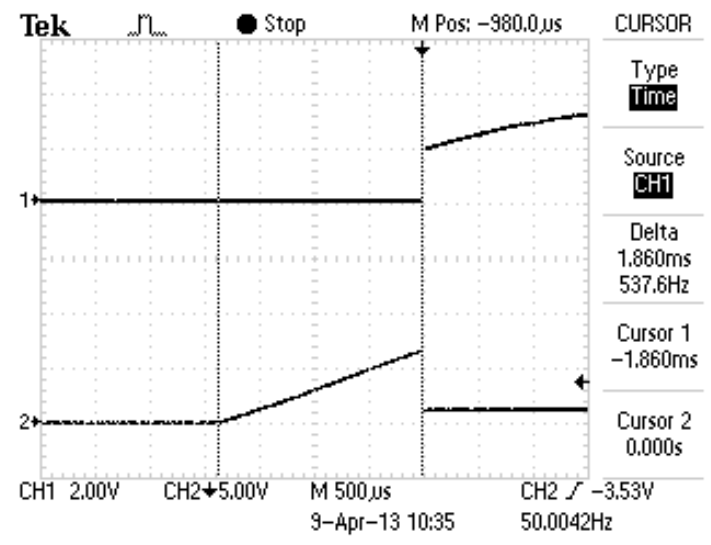

Fig. 6 time interval before irradiation

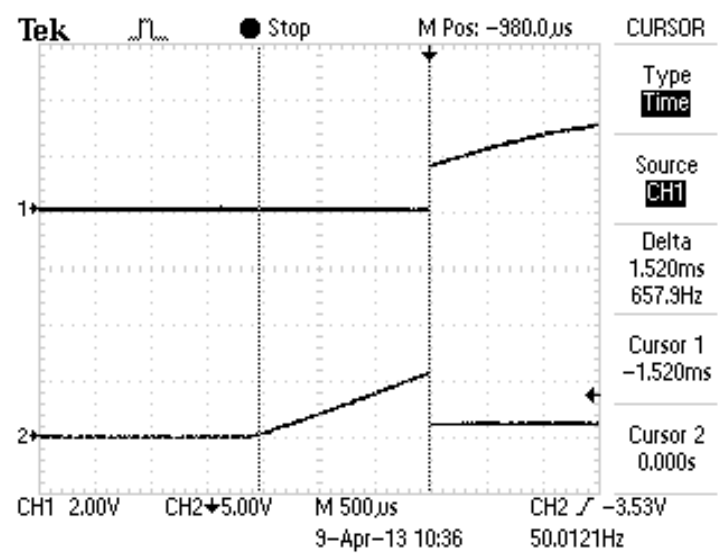

Fig.7 time interval change after irradiation

Irradiation was done using a low-power Co ${ }^{60}$ source at the time of peak voltage of the transistor.

Waveforms were taken with a dual beam remembering oscilloscope "Tektronix TDS 1002".

Without exposure to the specific values on the elements of the scheme voltage at which the inflection point reaches the VAX e $9.4 \mathrm{~V}$., (CH2, Pk-Pk) (Fig.4), but after irradiation, the voltage drops to $6.4 \mathrm{~V}$., (CH2, Pk-Pk) (Fig.5).

It also feels the substantial difference in voltage amplitude $\mathrm{V}_{\mathrm{EB} 1}$ with and without exposure ( 32\%).

The first beam (CH1) of the same waveform is shown and the change of the current through the transistor. Without irradiation it is $1.55 \mathrm{~V} / 510=$ $3.04 \mathrm{~mA}$, and then irradiation becomes $1 / 510=$ $1.96 \mathrm{~mA}$.

From these diagrams can be seen that the current climate is of the same order. These changes are sufficiently large to allow construction of radioisotope relays for various applications.

On the other hand switching time of the transistor also significantly changes. This is clearly seen in both the duration of the current and voltage impuls.

The range of change of the switching time of unijunction transistor due to irradiation can be seen from the diagrams in Fig.6 and Fig.7. Without irradiation time is $1.86 \mathrm{~ms}$. (Fig.6), and in irradiation falls to $1.52 \mathrm{~ms}$.(Fig.7).

This length can easily be measured and serve to quantization of the frequency-independent series of 
pulses. Thus, digital form of time measurement for change the current and voltage for proper calibration makes it possible to construct and measurement devices for various applications.

\section{CONCLUSION}

Incurred from the initial experiments can be concluded that exposure with gamma quanta to unijunction transistors change their volt-ampere characteristic widely (VAX), which is a precondition for further more depth research in order to optimize some parameters variables to an extent sufficient for use in the construction of both radioisotope relays and precision measuring equipment.
There is going to be the study of this type of transistors, which are operating in generator mode.

The results of these studies will be published soon.

\section{REFERENCES}

[1] Пугачев А.В., Е.В.Сахаров. Справочник по радиоизотопной автоматике.”Энергия”, Москва, 1974г.

[2] Мишев И.Т. Основи на съвременната радиационна дозиметрия."Техника",София, 1971

[3] Ненов.Н.Х. Учебно-методично ръководство за лабораторни упражнения по индустриална електроника. „ЕКС-ПРЕС”,Габрово,2010г.

[4] Petrova D., Fabrication Technologies and Economic Aspects for Components in Microtechnology, VII International scientific conference "Management and engineering'09" Sozopol, 22-24.06 2009, TU - Sofia, XVII, 3/113, June 2009, ISSN-1310-3946, pp. 306-312. 